Check for updates

Cite this: RSC Adv., 2019, 9, 21564

DOI: $10.1039 / c 9 r a 90053 e$

www.rsc.org/advances

\title{
Correction: An efficient one pot ipso-nitration: structural transformation of a dipeptide by $\mathrm{N}$ - terminus modification
}

\author{
Rajib Sarkar, Krishnendu Maji and Debasish Haldar*
}

Correction for 'An efficient one pot ipso-nitration: structural transformation of a dipeptide by $\mathrm{N}$-terminus modification' by Rajib Sarkar et al., RSC Adv., 2015, 5, 59570-59575.

The authors wish to clarify a few sentences by stating that the major product in the ipso-nitration reaction is probably the phenol 3 (Scheme 1). The ipso-nitration reaction happened in TFA, $\mathrm{NaNO}_{2}$ and $\mathrm{H}_{2} \mathrm{SO}_{4}$, which are comparatively drastic conditions for a peptide. Initially the yield of target compound 2 was $40 \%$. As we had a single crystal structure matching the structure of compound 2 , and the structure exactly matched with the mass spectroscopy data, we did not analyze the remaining $60 \%$ of the reaction product, which was likely phenol $\mathbf{3}$. Moreover, phenol $\mathbf{3}$ has the same formula and mass as our target compound 2 . We have been misled by this fact and did not analyze the reaction mixture further. The moderate yields may indeed indicate that the other product (phenol 3) could have been present which we have missed.<smiles>CCC(NC(=O)c1cccc([N+](=O)[O-])c1[N+](=O)[O-])C(=O)NC(CSc1cccc(O)c1)C(C)=O</smiles>

Scheme 1 The schematic presentation of possible products from the ipso-nitration of peptide 1 . Both products 2 and 3 have the same chemical formula and exact mass.

Ref. 14 should also be updated to include more relevant literature reports of ipso-nitration (ref. 14d-h in the article, presented here as ref. $1 a-e)$. In 1939, E. B. Starkey reported the replacement of an amine group by a nitro group through a diazotization reaction. ${ }^{1 a}$ In 1947 , Hodgson and co-workers reported the replacement of a diaxonium by a nitro group. ${ }^{1 b}$

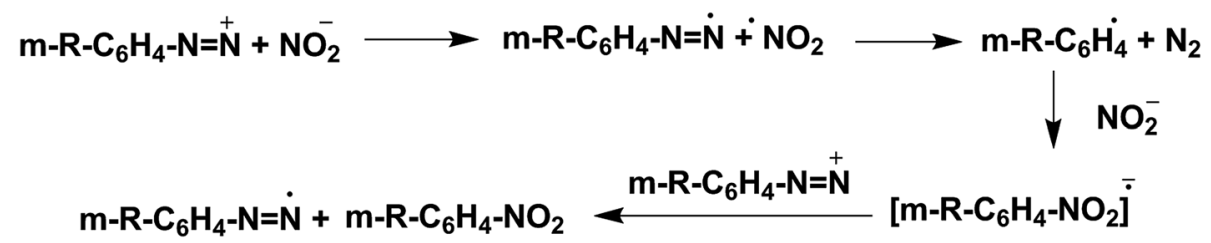

Scheme 2 The schematic of a radical mechanism adopted from Tetrahedron Lett., 1982, 23, 5191.

Department of Chemical Sciences, Indian Institute of Science Education and Research Kolkata, Mohanpur, India. E-mail: deba_h76@yahoo.com; deba_h76@iiserkol.ac.in; Fax: +913325873020; Tel: +913325873119 
Singh and co-workers proposed a radical mechanism (Scheme 2) for the ipso-nitration reaction. ${ }^{1 \boldsymbol{e}}$ Therefore, the mechanism we originally proposed in the article may not be correct, as we are unable to rule out the possibility that the reaction occurs via a radical mechanism.

The authors apologise for these errors and are indebted to an RSC Advances Board member and the editorial team for the exchange of information and the discussion regarding this corrigendum.

The Royal Society of Chemistry apologises for these errors and any consequent inconvenience to authors and readers.

\section{References}

1 (a) E. B. Starkey, Org. Synth., 1939, 19, 40; (b) H. H. Hodgson, A. P. Mahadevan and E. R. Ward, J. Chem. Soc., 1947, 1392; (c) L. I. Bagal, M. S. Pevzner and A. N. Frolov, Russ. J. Org. Chem., 1969, 5, 1767; (d) H. H. Hodgson, A. P. Mahadevan and E. R. Ward, Org. Synth., 1955, 3, 341; (e) P. R. Singh, R. Kumar and R. K. Khanna, Tetrahedron Lett., 1982, 23, 5191. 